\title{
Representing the Knowledge of Public Construction Project Cost Estimator by Using Rule-Based Method
}

\author{
Abelrahman Osman Elfaki ${ }^{1,2}$, Saleh Alatawi ${ }^{1,2}$ \\ ${ }^{1}$ University of Tabuk, Tabuk, KSA \\ ${ }^{2}$ Binladen Research Chair of Quality and Productivity Improvement in the Construction Industry, College of \\ Engineering, University of Hail, Hail, KSA \\ Email: a.elfaki@ut.edu.sa, satawi@ut.edu.sa
}

Received 23 November 2015; accepted 8 December 2015; published 11 December 2015

Copyright (C 2015 by authors and Scientific Research Publishing Inc.

This work is licensed under the Creative Commons Attribution International License (CC BY). http://creativecommons.org/licenses/by/4.0/

\section{c) (i) Open Access}

\begin{abstract}
Despite the presence of various construction project cost estimate softwares, human experience and knowledge cannot be disregarded. This fact has been proven in practice, where the success of construction cost estimate process is mainly based on knowledge of human estimator. The main question concerns what human knowledge determines the success of the construction cost estimation process. To address this question we have applied Delphi technique and the output is eleven factors that are enough to precisely represent construction cost estimator knowledge. Then we have used First Order Logic (FOL) to represent these factors in terms of predicates and rules. These FOL rules could be used for evaluating construction cost estimator knowledge in five classes: fail, pass, acceptable, good, and very good. As a validation process we have done experiments using history data and the results have proved the accuracy of our proposed method.
\end{abstract}

\section{Keywords}

Construction Management, Construction Cost Estimation, Rule-Based System

\section{Introduction}

Cost estimation is the most important preliminary process in any construction project. In the construction industry, cost estimation is the process of predicting the costs required to perform the work within the scope of the project [1]. Estimating the cost of the construction project is the step that determines the decision: whether or not to implement this construction project. Accordingly, the cost estimate plays a dangerous and key role in the project life cycle. Basically, the project's success depends mainly on the validity and accuracy of the financial 
cost estimate [2]. The previous discussion reflects the importance and impact of construction cost estimation process.

Although there are a significant number of automated construction cost estimation tools, humans still have the upper hand in estimating the cost of construction projects [3]-[5]. While the cost estimation process depends on human then there must be differences between estimates even in one project. In other words, even in one project and by using the same data and variables, different estimators could provide different cost estimations. This fact is due to variances in human expertise. From the previous fact, it is very clear that the accuracy of construction cost estimation is basically depending on the human estimator expertise, i.e., the good expertise provides accurate estimation.

In the literature, there are many works that deal with construction cost estimation by developing expert system. Expert system is a computer program that has an ability to behave in the same way as a human expert [6]. The final aim of creating and developing construction cost estimation expert system is to mimic the human expert by transferring the human expert to the software. Even with the usage of these Artificial Intelligence softwares, human experts stay irreplaceable. However, these artificial expert systems improve the estimation process in different perspectives such as compensating the numerical shortage of human experts, or using expert system as educational tools. The applications of expert systems have the lion's share among all other intelligent techniques.

Construction project cost estimation is an instance of a knowledge-intensive engineering task [7]. This knowledge depends on the expertise of the human professional. In fact, engineers require several years to develop the necessary expertise to conduct the cost estimation process. The main issue that arises here is that the engineers' expertise is often not documented or even authenticated. Hence, this expertise is prone to subjectivity (i.e., defined to an extent by one's personal opinion). According to Shane et al. (2009), accuracy and comprehensiveness in cost estimation are delicate issues and can be easily affected by many different parameters; furthermore, each parameter must be properly addressed in order to maintain an acceptable level of accuracy during the process [8]. Hence, it is very important to define clearly the factors that make human as an expert in estimating cost of construction project.

According to Akinci and Fischer (1998), the factors that affect cost estimation in construction projects can be clustered into two distinct groups: estimator-specific factors, and design and project-specific factors [9]. The estimator specific factors are defined as the factors that are related to construction cost estimators' background, experiences, and cognitive skills. On the other hand, design and project-specific factors are defined as factors that are related to construction project itself such as project size, type of project, ground conditions, type of client, material costs, likely design and scope changes, duration, and tendering method. The design and projectspecific factors could be easily computerized. In our previous work [10] we have investigated the intelligent techniques that have been developed based on design and project-specific factors. On the contrary, estimator specific factors still not yet have been defined. It is challenging to define precisely the estimator specific factors but it is crucial to understand how human-expert can deal with the process of estimating the cost of construction projects. Estimator specific factors also could be classified in two classes: knowledge and heuristics. Knowledge leads to skills developed over years from reading, learning and/or field experiences. Heuristics are cognitive rules which people often use to form judgments and make decisions [11]. Our target in this paper is human knowledge, not heuristics.

Although there are significant numbers of research papers that have discussed usage of the expert system in construction cost estimation process, there is no work that defined what these human factors are, which make a person be an expert in construction cost estimation, i.e., construction cost estimator. This fact encourages both research and industry to define the human factors that affect the decision in construction cost estimation. The benefits of recognizing the factors that contribute to the building of human experience in the field of estimating cost construction are considered of great help in measuring cost estimation methods.

The aim of this research is to determine, and then verify the human factors that affect estimation of the cost of a construction project as undoubtedly human expertise plays a key role in the success of this process. To the best of our knowledge, this is the first work that deals with the knowledge of construction project cost estimator.

\section{The Human Knowledge That Affects Construction Project Cost Estimation: Construction Cost Estimator Knowledge}

In the following section, we will represent the human knowledge that affect construction project cost estimation by human factors as knowledge (in any domain) could by represented as factors. To explore and define the 
knowledge that affects construction project cost estimation a Delphi methodology is used [12]. In the following, the details of our Delphi methodology have been presented. First, we have followed these steps to collect and refine the human factors: select group of target experts, acquire the first feedback from the experts, refine the collected work and redistribute it, and conduct final workshop. Hence, each step is expressed in depth.

Select group of target experts. This step is considered the most significant as the final results are mainly dependent on its selection. Fortunately, our research was carried out in Saudi Arabia due to the huge number of construction projects. Thus, we were able to find a great number of construction experts from different nationalities, backgrounds, ages and sufficient experience. Such a population ensured good sampling.

It is well known that construction projects can be classified into two groups: public and private. Regarding public projects, there are two Saudi ministries in charge: the Ministry of Urban and Rural Affairs and the Ministry of Transportation. This research used the contractors and consultants databases of the two ministries to target the relevant group of experts. We selected the suitable experts, from these databases of almost 5000 engineers, based on certain criteria developed from the study of Zavadskas et al. (2012) [13] and Dainty and Loosemore (2012) [14].

Refining and redistributing the collected work. In this phase, the suggested factors were collected through a blind process, i.e., the names of experts were hidden and replaced with numbers. All suggested human factors were checked and duplication in any context had been eliminated. Finally, the refined list was distributed to all our experts.

Conducting the final workshop. This was the last phase in our methodology. The experts were invited to participate for three days in workshops held at Tabuk University, Saudi Arabia. The human factors collected and refined from the previous phase were distributed among them. The experts discussed each factor which they voted to accept or reject. At the end, the workshop determined the human factors that affect construction cost estimation. In other words, these factors are representing knowledge of construction project cost estimator.

The outputs of the workshop are summarized below. The human experts had varying points. The accuracy of the construction cost estimation of the human expert is dependent on his knowledge with respect to these points.

1. Evaluation of the client. Previous experience with the client determines the project's level. Each client has preferences in terms of specifications. For instance, one client prefers a specific elevator brand regardless of price.

2. Knowledge of the complexity of the design. The content of the project's architectural design in terms of the difficulty or ease of implementation.

3. Knowledge of the competitors. Does the construction expert have appropriate knowledge about competitors? Knowledge can also assist in determining the cost by competitive prices.

4. Knowledge of the consultant. Does the construction expert have appropriate knowledge about the consultant? This knowledge should assist a contractor to determine the cost by competitive prices. For instance, consultants have various expectations. Previous knowledge of a consultant's expectation assists in providing more accurate cost.

5. Appropriate knowledge of the laws and regulations of the contractual process. Knowledge about the regulations and rules that are issued by authorities is crucially important. This type of knowledge assists a construction expert to estimate accurate cost.

6. Complete knowledge about the project location. A construction expert should be able to have full and in depth answers for questions such as: How difficult is it to transfer construction materials to the project's site? What is the current security situation? Could the weather cause any difficulties in the implementation of the project?

7. Knowledge of a contractor's financial situation. How can a construction expert assess a contractor's financial situation? For instance, does he know whether he has the necessary financial capacity for the project? Or what is the size of the loan which can be obtained from the bank? Would it be sufficient to complete the project? This knowledge assists an expert in providing suitable cost estimation.

8. Knowledge of the relationship between the contractor and subcontractor. A good relationship with subcontractors provides contractors with greater flexibility in determining the project's cost.

9. Knowledge of the current construction project's market situation. Knowing of relevance is the current market situation in terms of supply and demand. Such knowledge should guide experts to provide realistic cost estimation. 
10. Knowing how to find the skilled employees and technicians who are needed to make the construction project a success.

11. Knowledge of contractor's experience. The estimator should have knowledge of client experiences.

Table 1 shows the factors that represent estimator's knowledge with an instance for each factor. In fact, Table 1 shows in details what is the best knowledge that the construction cost estimator must have. As to the best of our knowledge, this is the first paper to define precisely what the meaning of construction cost estimation knowledge is.

\section{Rule Based Method}

In this section, the representation of construction cost estimator knowledge as knowledge based has been discussed. Any knowledge based consists of predicates and rules. We use First Order Logic (FOL) [15] to formalize construction cost estimator knowledge and this will allow using Prolog [16] as a reasoning tool. In the following, each one of the eleven knowledge factors that has been discussed in section 2 has been represented as a predicate.

As the whole issue it is about the knowledge of estimator, and then we identify the main predicate as "knowledge". We have designed the knowledge predicate to have three parameters: $\mathrm{s}, \mathrm{X}$, and $\mathrm{n}$. Where the letter "s" represents the construction cost estimator, the capital letter $\mathrm{X}$ represent any one of the eleven knowledge factors, and finally the letter " $n$ " represent the knowledge value. We have designed the knowledge value as an integer from 1 to 5 which reflect in order; very good, good, acceptable, pass and fail. As we have mentioned before, the capital letter " $X$ " the knowledge factors hence " $X$ " could be replaced by eleven factors. Table 2 shows the constants that represent knowledge factors.

Now, we could show the total set of predicates that could be used for representing knowledge of construction cost estimator. Table 3 shows the predicates that could be used representing knowledge of construction cost estimator.

Table 1. Estimator knowledge factors with examples.

\begin{tabular}{|c|c|}
\hline Knowledge Factor & Example \\
\hline Evaluation of the client & Knowing very well client preferences \\
\hline Knowledge of the complexity of the design & The architectural design for a building has very complicated curves \\
\hline Knowledge of the competitors & $\begin{array}{l}\text { Knowledge about the financial situation of a competitor could assist } \\
\text { an expert to estimate the tender price provided by a competitor }\end{array}$ \\
\hline Knowledge of the consultant & $\begin{array}{l}\text { Knowing that this consultant prefer and trust } \\
\text { only local materials and equipment }\end{array}$ \\
\hline $\begin{array}{l}\text { Appropriate knowledge of the laws } \\
\text { and regulations of the contractual process }\end{array}$ & $\begin{array}{l}\text { Can the construction work continue } 24 \text { hours even } \\
\text { with different working shifts? Is there any advance payment }\end{array}$ \\
\hline Complete knowledge about the project location & $\begin{array}{l}\text { The estimator knows that his project will be held in the high } \\
\text { mountains where there are no transportation routes. You must use } \\
\text { air transport to deliver the required equipment to the project site }\end{array}$ \\
\hline Knowledge of a contractor's financial situation & $\begin{array}{c}\text { The estimator knows that the contractor has finical problem } \\
\text { and the contactor needs very badly this project } \\
\text { so he will minimize the profit as much as he can }\end{array}$ \\
\hline $\begin{array}{l}\text { Knowledge of the relationship } \\
\text { between the contractor and subcontractor }\end{array}$ & $\begin{array}{c}\text { The estimator knows the degree of relationship between contractor and } \\
\text { subcontractor. For instance, is the contractor could assign work to } \\
\text { subcontractor without initial payment? Or is the contractor could } \\
\text { determine the net profit to the subcontractor? }\end{array}$ \\
\hline $\begin{array}{l}\text { Knowledge of the current construction } \\
\text { project's market situation }\end{array}$ & $\begin{array}{l}\text { For example, are there expectations of an increase } \\
\text { in prices of construction materials? }\end{array}$ \\
\hline $\begin{array}{l}\text { Knowing how to find the skilled employees } \\
\text { and technicians who are needed to } \\
\text { make the construction project a success }\end{array}$ & $\begin{array}{l}\text { The estimator knows that the local employees and technician } \\
\text { do not have previous experiences in this type of project. } \\
\text { Also, he knows that Indian employments companies could } \\
\text { provide him with the required employees and technician }\end{array}$ \\
\hline $\begin{array}{l}\text { Knowledge of contractor's experience } \\
\text { The estimator should have knowledge of client experiences }\end{array}$ & $\begin{array}{l}\text { The estimator knows if the contactor has previous } \\
\text { experience of the same type of construction project or no }\end{array}$ \\
\hline
\end{tabular}


Table 2. The constants that represent knowledge factors.

\begin{tabular}{|c|c|c|}
\hline \# & Knowledge Factor & Representation Constant \\
\hline 1 & Evaluation of the client & Word: “client” \\
\hline 2 & Knowledge of the complexity of the design & Word: “complexity” \\
\hline 3 & Knowledge of the competitors & Word: “competitor” \\
\hline 4 & Knowledge of the consultant & Word: “consultant” \\
\hline 5 & Appropriate knowledge of the laws and regulations of the contractual process & Word: "law” \\
\hline 6 & Complete knowledge about the project location & Word: "location” \\
\hline 7 & Knowledge of a contractor's financial situation & Word: “financial” \\
\hline 8 & Knowledge of the relationship between the contractor and subcontractor & Word: “subcontractor” \\
\hline 9 & Knowledge of the current construction project's market situation & Word: "market” \\
\hline 10 & $\begin{array}{l}\text { Knowing how to find the skilled employees and technicians } \\
\text { who are needed to make the construction project a success }\end{array}$ & Word: “employee” \\
\hline 11 & Knowledge of contractor's experience. The estimator should have knowledge of client experiences & Word: “experience” \\
\hline
\end{tabular}

Table 3. Knowledge factors and its associated predicates.

\begin{tabular}{|c|c|c|}
\hline \# & Knowledge Factor & Predicate \\
\hline 1 & Evaluation of the client & knowledge (s, client, n); \\
\hline 2 & Knowledge of the complexity of the design & knowledge (s, complexity, n); \\
\hline 3 & Knowledge of the competitors & knowledge (s, competitor, n); \\
\hline 4 & Knowledge of the consultant & knowledge (s, consultant, n); \\
\hline 5 & Appropriate knowledge of the laws and regulations of the contractual process & knowledge (s, law, n); \\
\hline 6 & Complete knowledge about the project location & knowledge (s, location, n); \\
\hline 7 & Knowledge of a contractor's financial situation & knowledge (s, financial, n); \\
\hline 8 & Knowledge of the relationship between the contractor and subcontractor & knowledge (s, subcontractor, n); \\
\hline 9 & Knowledge of the current construction project's market situation & knowledge (s, market, n); \\
\hline 10 & $\begin{array}{l}\text { Knowing how to find the skilled employees and technicians } \\
\text { who are needed to make the construction project a success }\end{array}$ & knowledge (s, employee, n); \\
\hline 11 & $\begin{array}{l}\text { Knowledge of contractor's experience. } \\
\text { The estimator should have knowledge of client experiences }\end{array}$ & knowledge (s, experience, n); \\
\hline
\end{tabular}

Table 4 shows the rules for knowledge (s, client, $n$ ) predicate which we presented as an example for the reset of ten predicates. Each factor of the eleven has the same format that has been presented in Table 4, i.e., five rules for each predicate. Generally the rules in Table 4 say that: for all estimators and clients there exists an integer that illustrates the estimator knowledge about the client. The syntaxes and semantics of our proposed predicates have been presented in Table 4.

\section{Validation}

To validate our proposed method (predicates and rules) and check their accuracy and suitability for estimating construction cost, an experiment was carried out. We were given permission to use confidential information from 25 large Saudi public construction projects. Information was also collected from the Ministry of Urban and Rural Affairs and the Ministry of Transportation. Each project represented one experiment described below: 
Table 4. Rules for knowledge (s, client, n) predicate.

\begin{tabular}{|c|c|}
\hline Rule Syntax & Rule Semantic \\
\hline$\forall s$, client, $\exists n$ : knowledge (s, client, n) $\wedge \mathrm{n}=1 \Longrightarrow$ fail; & $\begin{array}{l}\text { If the estimator knowledge about client is equal to } \\
1 \text { then output equal fail. }\end{array}$ \\
\hline$\forall s$, client, $\exists n$ : knowledge (s, client, $\mathrm{n}) \wedge \mathrm{n}=2 \Longrightarrow$ pass; & $\begin{array}{l}\text { If the estimator knowledge about client is equal to } \\
2 \text { then output equal pass. }\end{array}$ \\
\hline$\forall$ s, client, $\exists n$ : knowledge (s, client, $\mathrm{n}) \wedge \mathrm{n}=3 \Longrightarrow$ acceptable; & $\begin{array}{l}\text { If the estimator knowledge about client is equal to } \\
3 \text { then output equal acceptable. }\end{array}$ \\
\hline$\forall \mathrm{s}$, client, $\exists n$ : knowledge (s, client, n) $\wedge \mathrm{n}=4 \Rightarrow$ good; & $\begin{array}{l}\text { If the estimator knowledge about client is equal to } \\
4 \text { then output equal good. }\end{array}$ \\
\hline$\forall$ s, client, $\exists n$ : knowledge (s, client, n) $\wedge$ n $=5 \Rightarrow$ very good; & $\begin{array}{l}\text { If the estimator knowledge about client is equal to } \\
5 \text { then output equal very good. }\end{array}$ \\
\hline
\end{tabular}

1. We have collected a group of 78 construction cost estimator from the data-base of Ministry of Urban and Rural Affairs and the Ministry of Transportation. They join and contribute to this experiment as volunteers.

2. The selected construction cost estimators have been divided into five classes. These five classes were: very good, good, acceptable, pass and fail.

3. For each project of the selected 25 projects, the classes were divided based on the specific characteristics of each group. For instance, in the first experiment, any expert who satisfied the characteristics of knowledge factors as very good (with respect to the first project) was assigned to the very good class. Any construction cost estimator who satisfied the characteristics of knowledge factors as good (with respect to the first project) was assigned to the good class. This was the same concept for the acceptable, pass and fail classes.

4. The experiment began by distributing information about a project to all our selected construction cost estimators. Then, a self-evaluation process allowed each expert to evaluate himself with respect to the 11 knowledge factors by using the distributed project's information. The measurement was based on five scales: 100 - 90, 89 - 75, 74 - 60, 59 - 50, 50 - 0. For instance, in regard to the first factor, "Evaluation of the client", each expert scored himself using the project's information from 100 - 0 . As an example, if an expert felt that he could evaluate correctly the client by $90 \%$ then he scored himself 90 , or 70 if he could evaluate the client correctly by $70 \%$. The expert should also evaluate his knowledge on each knowledge factor. Finally, the average was used to assign each expert to a suitable class. For instance, an expert with an average score of 70 would be assigned to acceptable class.

5. After classes were divided, each class could estimate the cost of a project.

From the results of the 25 experiments we found that the estimation accuracy of the very good class was $92 \%$, the good class was $83 \%$, the acceptable class was $61 \%$, the pass class was $49 \%$ and the fail class was $20 \%$. These results confirm the accuracy of our proposed method.

\section{Conclusions}

Our proposed predicates and rules will provide a great advantage for construction cost community. For instance, by using our proposed modeling, the strengths and weakness of any construction cost estimation should be known. In addition, more than one construction cost estimator could be working together to complement each other.

The first contribution of this paper is to introduce knowledge based predicates and rules that could be used for representing knowledge of construction cost estimator.

Experiments have validated and proved the accuracy of our contributions. To the best of our knowledge, this is the first research to tackle this issue.

\section{Acknowledgements}

The present research has been undertaken under the direction of the "Binladin Research Chair on Quality and Productivity Improvement in the Construction Industry" at the University of Hail, funded by the Saudi Binladin Constructions Group. 


\section{References}

[1] Holm, L., Schaufelberger, J.E., Griffin, D. and Cole, T. (2005) Construction Cost Estimating: Process and Practices. Pearson Education, Upper Saddle River.

[2] Ma, Z., Liu, Z. and Wei, Z. (2015) Formalized Representation of Specifications for Construction Cost Estimation by Using Ontology. Computer-Aided Civil and Infrastructure Engineering, Published Online. http://dx.doi.org/10.1111/mice.12175

[3] Flyvbjerg, B., Holm, M.S. and Buhl, S.L. (2002) Underestimating Costs in Public Works Projects: Error or Lie? Journal of the American Planning Association, 68, 279-295. http://dx.doi.org/10.1080/01944360208976273

[4] Taroun, A. (2014) Towards a Better Modelling and Assessment of Construction Risk: Insights from a Literature Review. International Journal of Project Management, 32, 101-115. http://dx.doi.org/10.1016/j.ijproman.2013.03.004

[5] Jing, D. and El-Gafy, M. (2015) Human Computation Enabled Organizational Learning in the Face of Deep Uncertainty: Example of Conceptual Estimating. Journal of Information Technology in Construction, 20, 275.

[6] Peter, J. (1998) Introduction to Expert Systems. 3rd Edition, Addison Wesley, New York, 2.

[7] French, S.S., Martin, F. and John, K. (2003) A Generic Feature Driven Activity-Based Cost Estimation Process. Advance Engineering Informatics, 17, 23-39. http://dx.doi.org/10.1016/S1474-0346(03)00017-X

[8] Shane, S.J., Molenaar, K.R., Anderson, S. and Schexnayder, C. (2009) Construction Project Cost Escalation Factors. Journal of Management in Engineering, 25, 221-229. http://dx.doi.org/10.1061/(ASCE)0742-597X(2009)25:4(221)

[9] Akinci, B. and Fischer, M. (1998) Factors Affecting Contractors’ Risk of Cost Overburden. Journal of Management in Engineering, 14, 67-77. http://dx.doi.org/10.1061/(ASCE)0742-597X(1998)14:1(67)

[10] Elfaki, O.A., Alatawi, S. and Abushandi, E. (2014) Using Intelligent Techniques in Construction Project Cost Estimation: 10-Year Survey. Advances in Civil Engineering, 2014, Article ID: 107926. http://dx.doi.org/10.1155/2014/107926

[11] Lewis, A. (2008) The Cambridge Handbook of Psychology and Economic Behaviour. Cambridge University Press, Cambridge. http://dx.doi.org/10.1017/CBO9780511490118

[12] Rowe, G. and Wright, G. (2001) Expert Opinions in Forecasting. Role of the Delphi Technique. In: Armstrong, Ed., Principles of Forecasting: A Handbook of Researchers and Practitioners, Kluwer Academic Publishers, Boston.

[13] Zavadskas, E.K., Vainiūnas, P., Turskis, Z. and Tamošaitienė, J. (2012) Multiple Criteria Decision Support System for Assessment of Projects Managers in Construction. International Journal of Information Technology \& Decision Making, 11, 501-520. http://dx.doi.org/10.1142/S0219622012400135

[14] Dainty, A. and Loosemore, M. (2012) Human Resource Management in Construction: Critical Perspectives. 2nd Edition, Routledge, New York.

[15] Walicki, M. (2006) Introduction to Logic. Lecture Notes Online. http://www.econphd.net/notes.htm

[16] Wielemaker, J. (2007) SWI-Prolog (Version 5.6.36). Free Software, University of Amsterdam, Amsterdam. 